\title{
Biomechanical Analysis of Dunks Technology
}

\author{
Daliang Zhou* \\ School of P.E, Nanjing XiaoZhuang University, Nanjing 210000, Jiangsu, China
}

\begin{abstract}
The main purpose of this study is biomechanical analysis of dunks technology, mainly through basketball players bounce force biomechanical analysis and endurance to dunk a basketball biomechanical analysis of two aspects to carry on the research, which can provide the basis for the future basketball teaching and training. Research methods are: access to the data method, the technology of spot statistics, analysis and data processing method. This paper takes the young men's basketball team of Heilongjiang province and the Harbin Institute of Physical Education men's basketball team as the research object, the method of combining Nonn Cybex with multi joint velocity measurement and motion video recording that is adopted, biomechanical analysis on athletes standing vertical jump, step jump and isokinetic strength characteristics of the spring force. By quoting Richard C. Nelson American sports biomechanics expert results, watching the $18^{\text {th }}$ Championship Men's basketball video and statistics of CBA13-14 season games, according to the analysis and research of air volleyball technology, we can study the mechanics of the basketball movement endurance to dunk a basketball analysis.
\end{abstract}

Keywords: Athlete, biomechanical, dunks technology, hover, measurement.

\section{INTRODUCTION}

Basketball was invented in 1891 when basket height was defined as the 3.05 meters. From then on, the basketball game is in "ground" and "high altitude", height and speed of the race. Ground advantage is mainly reflected in the speed; air superiority is mainly reflected in a variety of high technology, of which the most representative is dunk. Tall and with good jumping players can holding above the rim to pour into the inside of the basket to the basketball, this technique in modern is recognized for is the most stable and most difficult to defend and very encouraged by the morale of the score. So far, domestic a dunk technology application research also less only studied the dunk technology and its related physical quality development and training, and to dunk action for biomechanical analysis also belong to the basic blank field. This thesis is to study the biomechanical dunk of discourse analysis, provide a theoretical basis for the research on the later dunk [1-3].

The rapid development of modern technology and sports technology has undoubtedly been linked with the degree of sports science. All the sports powers believe that the level of technology depends on the emphasis on sports scientific research and the application of the results, so as to improve the basketball training level, we must pay attention to the basketball theory research.

\section{COMMENTS ON THE RESEARCH METHODS OF SPORTS BIOMECHANICS}

\subsection{Theoretical Research Method}

The key of the research on the sports biomechanics is to establish the mechanics model of human movement. The research method of theory is mainly to explore the law of human movement. Its object, purpose, method and research result are different from the experimental method. The object of theoretical research is abstract human body model, which is to reveal the movement law, and the core is the derivation of the classical mathematics mechanics, and the conclusion is the inner mechanism of the movement. The mathematical model of human movement is the main method of theoretical research. Since the 80 time in twentieth Century, there are many new breakthroughs and progresses in the method of mathematical model, but the method of mathematical model of human body movement has not been widely used in China [4-7].

At present, the sports biomechanics is mainly to study the human internal motion system and the performance of the external human body as a whole mechanical movement features. In order to facilitate the research, the key of the sports biomechanics theory is to establish the motion model to describe the movement.

In general, there are two kinds of methods: the first is human body system simulation research method, the representative of the haze South Africa mechanical college; the second method is application of more rigid body system dynamics theory to establish the mechanical model, the representative is the mechanical expert Kane. In the research of sports biomechanics, the motion of most mechanics system is controlled by Newton's law of motion. The model is the mathematical form of Newtonian mechanical system. But Newtonian mechanics is clearly not suitable for living in vivo, which has been proved by theory or practice. So the mechanical characteristics of the mechanical characteristics of the muscle, bone, and the mechanical characteristics of the joint system and the relationship between the mechanical characteristics and the motion of the human body and the motion of the system are also very difficult [8-10]. 
The rapid development of modern competitive sports technology is undoubtedly linked with the degree of Physical Education. All the sports powers believe that the competitive level depends on the emphasis on sports scientific research and the application of the results to improve the level of basketball training, must pay attention to basketball theory research. In this paper, through the analysis of hover dunk and basketball player on the biomechanics of the bounce to prove that mechanical factors involved in influencing the basketball dunk.

\subsection{Experimental Research Method}

Three special events in the history of biomechanics are: 1 . in 1877, American photographer Muybridge used 24 camera shooting the horse that run animations successive photographs, subsequently filmed consecutive pictures of human walking, running and other movements, so as to lay a solid foundation for the method of image measurement and analysis.2. At the beginning of the 20th century German anatomist Blavin Braune and Fisher used corpse anatomical measurements of the human body inertia parameters, and based on this established the first human quality distribution model, so as to lay a solid foundation for the quantitative analysis of human motion.3. In the 1930s, British physiologist Hill measured the relationship between muscular tension and speed, and the reasonably consistent with the experimental results of the Hill equation that is established based on the principle of thermodynamics. Hill's classic work on muscle contraction which lays the theoretical foundation of muscle mechanics $[11,12]$.

The experimental research methods and theoretical research methods compared with slightly more mature, which are the following features:1. Along with the progress of engineering technology, the means is becoming more and more diversified. From the "traditional" photography technology development to three-dimensional photography, has been able to more accurately reflect the motion characteristics of things, and many new modern technology and equipment has also been applied to the study of biomechanics, such as laser aiming test analysis system, The image analysis system of the motion picture of the love movement, six dimensional measuring force platform SAEMS- $t$, four channel telemetry EMG, universal material test machine etc. 2. The method of laboratory measurement and motion field measurement are combined. Mature measurement method has two kinds: one is under the laboratory conditions, the various types of dynamometer and advanced multifunctional muscle strength measurement system, and sports which related major muscle groups for quantitative measurement. This method can be referred to as the "laboratory measurement method. The other is to measure the athlete's special strength training level by means of training instrument or athletes special strength training, and this method can be called "motion measurement method" $[13,14]$.

\section{BIOMECHANICAL STUDY OF HOVER DUNK}

\subsection{Analysis of Basketball PLayers Could Dunk Tech- nology}

The flight route after the human body jumps depends on his departure from the ground, especially takeoff angle, height and speed of takeoff. Athletes once the take-off can obtain much endurance time? According to the information shows that: height $1.90 \mathrm{~m}$ volleyball player, if place bounce LM, you must get $4.5 \mathrm{~m} / \mathrm{s}$ initial velocity jump $(v=\sqrt{2 g h}=\sqrt{5}=4.47)$. It can get $0.22 \mathrm{~s}$ endurance time. After take-off due to the lift arm and leg lift, center of gravity increased $6 \mathrm{~cm}$, is actually his jumping height than jump after natural stretch down $6 \mathrm{~cm}$, in exchange for the body is relatively stable in the air position 0.22 seconds, and the 0.22 seconds is enough to do a hover dunk action. For the time, is to reduce the height of spring based.

In basketball, dunk requirements as far as possible to reduce the squat stage takeoff time, require fast jump, in a very short period of time a certain power generally squat muscle contraction and pedal force in the knee joint angle is large. Such as the squat jump shallow knee extension by short distance, muscle contraction and contraction pedal time, acceleration, and composite speed value is increased, the take-off speed faster, jump higher. I think according to the results of theoretical analysis, the best basketball player off when the knee angle should be shallow. From the perspective of mechanical squat, can taking a certain speed and the longest time, but it needs to take off when the time is too long, the basketball player is not applicable.

Richard C. Nelson used image analysis method of basketball players hover technology research and analysis. The results show that: (1) hover force as theoretical hypothesis is existing things; (2) endurance technology basic principle within a relatively short period of time can learn it. In short, when the focus in a predetermined throwing objects run, the athletes complete "hover" except for lower limb movements, if the athlete and adjust the position of the arm and ball, the center of gravity in the trunk and the lifting distance also increased, "hover" time will be extended, as shown in Fig. (1) and (2).

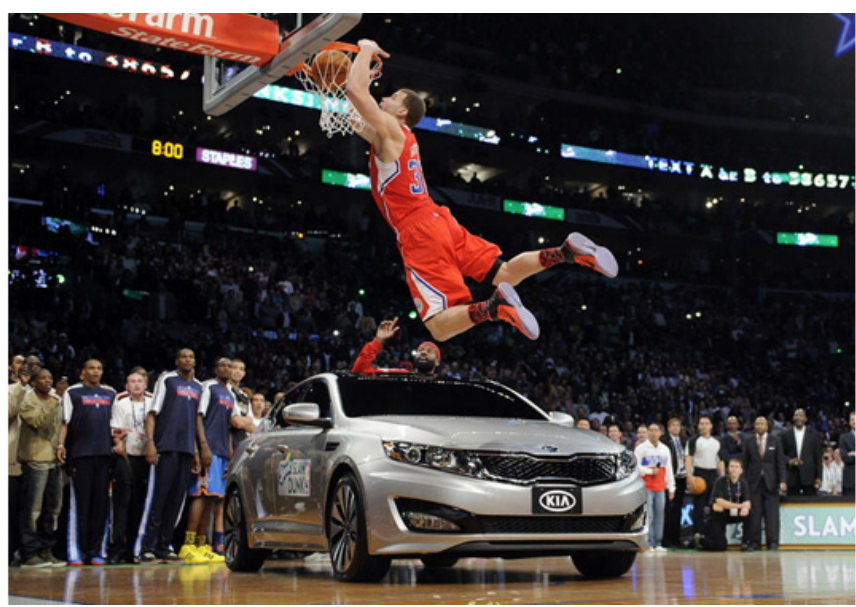

Fig. (1). The center of gravity to run at a predetermined parabola.

Fig. (1) shows the center of gravity to run at a predetermined parabola, the endurance athletes completely.

Fig. (2) shows the athletes adjust the arm and ball position, the center of gravity in the body and the lifting distance also increased, "hover" time is prolonged.

In the CBA13-14 season, Bayi team of the three games were observed statistics, and see Tables 1-3. 


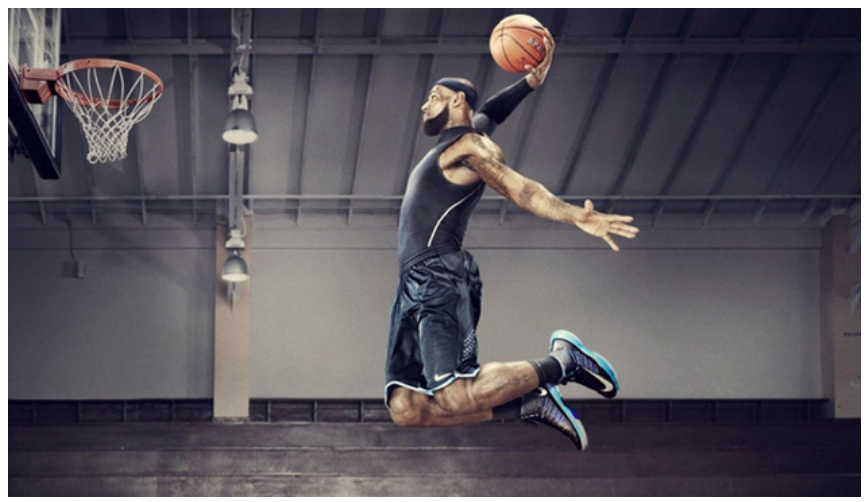

Fig. (2). The athletes adjust the arm and ball position.

By three games, we can see, the Bayi rockets each players can master the technique of endurance, and by the above statistics can be seen, they dunk basically are near the area of 3 seconds, after leaping catch dunk and dribble jump to dunk. Defensive follow jump cover, the impact of the release curve or very difficult to sell, can use vertical time difference and the body in the horizontal movement of the air, opened and defender of the distance, and try to stay in the air for some time, when the opponent's center of gravity will drop, and then dunk. They very well use the rule in the basket close to the opponent's body, using special aloft to dunk, even if the occurrence of foul body contact, does not affect the dunk action, for the three points. Statistics from the above results we can see Bayi rockets dunk hit rate is very high, every game is more than $50 \%$, visible so many chances to dunk and hit rate, is not an accident, it must control through a system of training to. From three games can be found, Shandong team and the Shanghai team in 3 seconds near the dunk was often cover each other, this can not be said after the two teams dunk technology difference, the author thinks that the main reason is poor hover force players, dunk doesn't make good use of the time difference, it was the truncation [15].

\section{ANALYSIS OF THE BOUNCING BIOMECHANICS}

\subsection{Research Object}

Select the youth basketball team in Heilongjiang Province, Harbin Institute of Physical Education men's basketball team (hereinafter referred as $\mathrm{Hei}$ and $\mathrm{Ha}$ ) as the research object. There are 10 players in each team, a total of 20 athletes.

\subsection{Research Methods}

By means of literature, expert interview, kinematic measurement, constant speed muscle test and mathematical statistics, the subjects were studied.

Table 1. Bayi team - Liaoning team (Note: statistical Bayi).

\begin{tabular}{|c|c|c|c|c|c|c|}
\hline \multirow{2}{*}{$\begin{array}{c}\text { Shooting Team } \\
\text { Number }\end{array}$} & \multirow{2}{*}{$\begin{array}{c}\text { Hover Dunk } \\
\text { (Number) }\end{array}$} & \multicolumn{2}{|c|}{ Hit (Number) } & \multicolumn{2}{|c|}{ Not hit (Number) } \\
\cline { 3 - 7 } & In the Paint & Postups & In the Paint & Postups \\
\hline \hline 6 & 7 & 2 & 1 & 3 & 1 \\
\hline 10 & 6 & 2 & 1 & 3 & 1 & - \\
\hline 11 & 7 & 4 & - & 2 & 1 & 1 \\
\hline 5 & 3 & 2 & 1 & 1 & 2 & 1 \\
\hline 13 & 3 & 4 & - & 12 & 4 \\
\hline
\end{tabular}

Table 2 Bayi team - Shangdong team (Note: statistical Bayi).

\begin{tabular}{|c|c|c|c|c|c|c|}
\hline \multirow{2}{*}{$\begin{array}{c}\text { Shooting Team } \\
\text { Number }\end{array}$} & \multirow{2}{*}{$\begin{array}{c}\text { Hover Dunk } \\
\text { (Number) }\end{array}$} & \multicolumn{2}{|c|}{ Hit (Number) } & \multicolumn{2}{|c|}{ Not Hit (Number) } \\
\cline { 3 - 7 } & In the Paint & Postups & In the Paint & Postups \\
\hline \hline 4 & 2 & 1 & - & - & 2 \\
\hline 6 & 8 & 3 & 2 & 2 & 2 \\
\hline 10 & 10 & 4 & 1 & - & 2 \\
\hline 11 & 3 & 2 & 1 & 2 & - \\
\hline 14 & 5 & 1 & 1 & - & 2 \\
\hline
\end{tabular}


Table 3. Bayi team - Shanghai team (Note: statistical Bayi)

\begin{tabular}{|c|c|c|c|c|c|c|}
\hline \multirow{2}{*}{$\begin{array}{l}\text { Shooting team } \\
\text { Number }\end{array}$} & \multirow{2}{*}{$\begin{array}{l}\text { Hover Dunk } \\
\text { (Number) }\end{array}$} & \multicolumn{2}{|c|}{ Hit (Number) } & \multicolumn{2}{|c|}{ Not Hit (Number) } & \multirow{2}{*}{ Hit Rate\% } \\
\hline & & In the Paint & Postups & In the Paint & Postups & \\
\hline 4 & 3 & 2 & - & 1 & - & \\
\hline 5 & 2 & 2 & - & - & - & \\
\hline 6 & 6 & 3 & - & 2 & 1 & \\
\hline 7 & 7 & 3 & - & 2 & 1 & \\
\hline 10 & 3 & - & 1 & 2 & - & \\
\hline 11 & 1 & - & - & 1 & - & \\
\hline 13 & 5 & 2 & 1 & 2 & - & \\
\hline 14 & 3 & 2 & - & 1 & - & \\
\hline Total & 28 & 14 & 2 & 12 & 2 & 50 \\
\hline
\end{tabular}

Table 4. The weak side leg's three joint flexor peak torque control table $(\mathrm{N} \times \mathrm{m} / \mathrm{kg})$.

\begin{tabular}{|c|c|c|c|c|c|c|c|c|c|c|}
\hline \multirow[t]{2}{*}{ Joint } & & \multicolumn{2}{|c|}{$60 \% \mathrm{CON})$} & \multirow{2}{*}{$\mathbf{P}$} & \multicolumn{2}{|c|}{$180 \%$ CON) } & \multirow{2}{*}{$\mathbf{P}$} & \multicolumn{2}{|c|}{$300 \%$ CON) } & \multirow{2}{*}{$\mathbf{P}$} \\
\hline & & Hei & Ha & & Hei & Ha & & Hei & Ha & \\
\hline \multirow[t]{2}{*}{ Hip } & $\mathrm{X}$ & 2.84 & 2.68 & $>0.05$ & 2.45 & 2.37 & $>0.05$ & 1.54 & 1.51 & $>0.05$ \\
\hline & $\mathrm{S}$ & 0.28 & 0.12 & & 0.10 & 0.10 & & 0.07 & 0.07 & \\
\hline \multirow[t]{2}{*}{ Knee } & $\mathrm{X}$ & 2.40 & 2.21 & $>0.05$ & 2.00 & 1.83 & $>0.05$ & 1.29 & 1.19 & $>0.05$ \\
\hline & $\mathrm{S}$ & 0.15 & 0.18 & & 0.10 & 0.19 & & 0.10 & 0.06 & \\
\hline \multirow[t]{2}{*}{ Ankle } & $\mathrm{X}$ & 0.51 & 0.48 & & 0.34 & 0.33 & $>0.05$ & 0.32 & 0.31 & $>0.05$ \\
\hline & $\mathrm{s}$ & 0.03 & 0.11 & & 0.01 & 0.01 & & 0.01 & 0.01 & \\
\hline
\end{tabular}

Table 5. The weak side leg's three joint extensor peak torque control table $(\mathrm{N} \times \mathrm{m} / \mathrm{kg})$.

\begin{tabular}{|c|c|c|c|c|c|c|c|c|c|c|}
\hline \multirow[t]{2}{*}{ Joint } & & \multicolumn{2}{|c|}{$60^{\circ} / \mathrm{s}$ CON) } & \multirow{2}{*}{$\mathbf{P}$} & \multicolumn{2}{|c|}{$180 \%$ CON) } & \multirow{2}{*}{$\mathbf{P}$} & \multicolumn{2}{|c|}{$300 \%$ CON) } & \multirow{2}{*}{$\mathbf{P}$} \\
\hline & & Hei & Ha & & Hei & Ha & & Hei & Ha & \\
\hline Hip & $X$ & 4.03 & 3.58 & $<0.01$ & 3.84 & 3.71 & $<0.05$ & 2.88 & 2.76 & $<0.05$ \\
\hline & S & 0.29 & 0.40 & & 0.12 & 0.18 & & 0.08 & 0.11 & \\
\hline Knee & $\mathrm{X}$ & 3.65 & 3.32 & $<0.05$ & 2.71 & 2.54 & $<0.05$ & 1.65 & 1.59 & $<0.05$ \\
\hline & S & 0.18 & 0.39 & & 0.20 & 0.11 & & 0.09 & 0.04 & \\
\hline Ankle & $\mathrm{X}$ & 1.24 & 1.04 & $<0.05$ & 0.53 & 0.49 & $<0.05$ & 0.46 & 0.43 & $<0.01$ \\
\hline & $\mathrm{s}$ & 0.13 & 0.21 & & 0.02 & 0.04 & & 0.01 & 0.03 & \\
\hline
\end{tabular}

\subsection{Results and Analysis}

According to the characteristics of basketball, 20 subjects in the vertical jump and step jump action were taken and analytical. The results show that: standing vertical jump height of gravity center height. Hei was $66.4+3.8 \mathrm{~cm}$, Ha is $62.1+1.7 \mathrm{~cm}$; vertical jump of center of gravity, Hei for $71.8+3.2 \mathrm{~cm}$. HA was $67.9+2.3 \mathrm{~cm}$, two groups there were very significant difference $(\mathrm{P}<0.01)$ that two groups of athletes in feet at the same time take-off, jumping ability is not in the same level.
Bending and stretching shares concentric contraction relative peak torque of comparative analysis in the study found that two groups of athletes, leg extensor force centripetal contraction of relative peak torque difference is small, at the same level. However, the weak lateral leg has a big difference, so the research only has the strength of the weak lateral leg of the athlete. Results see Table $\mathbf{4}$ and $\mathbf{5}$.

From Table $\mathbf{4}$ and $\mathbf{5}$ we can see: two groups of athletes on the weak side leg flexor and extensor muscle concentric contraction relative mean of peak torque increases with the 
Table 6. Two groups of athletes knee flexor, extensor centrifugal contraction peak torque control table $(\mathbf{N} \times \mathbf{m} / \mathbf{k g})$.

\begin{tabular}{|c|c|c|c|c|c|}
\hline \multirow{2}{*}{ Group } & & \multicolumn{2}{|c|}{ Leg force $180^{\circ} / \mathrm{s}(\mathrm{ECC})$} & \multicolumn{2}{|c|}{ Weak side leg $180^{\circ} / \mathrm{s}(\mathrm{ECC})$} \\
\hline & & Flexor & Extensor & Flexor & Extensor \\
\hline \multirow[t]{2}{*}{ Hei } & $\mathrm{X}$ & 2.40 & 4.19 & 2.27 & 4.09 \\
\hline & $\mathrm{s}$ & 0.36 & 0.46 & 0.39 & 0.39 \\
\hline \multirow[t]{2}{*}{$\mathrm{Ha}$} & $\mathrm{X}$ & 2.17 & 3.77 & 2.10 & 3.58 \\
\hline & $\mathrm{s}$ & 0.18 & 0.36 & 0.24 & 0.33 \\
\hline $\mathrm{P}$ & & $>0.05$ & $<0.05$ & $>0.05$ & $<0.01$ \\
\hline
\end{tabular}

speed of movement is a downward trend, and $\mathrm{Yu}$ Zhonggan's study results are consistent. Knee joint flexor three speed test from the relative peak torque mean black athletes were higher than $\mathrm{Ha}$ athletes and in three test speed this difference reached significant level $(\mathrm{P}<0.05)$, that black athletes weak side leg knee joint flexor muscle strength level strong $\mathrm{Ha}$ in athletes. Extensor, the weak side, hip and leg, ankle extensors concentric contraction relative peak torque mean in the three test speed, black athletes were higher than $\mathrm{Ha}$ athletes and there was a significant difference, especially hip maximum strength and fast strength of ankle joint difference is very significant $(\mathrm{P}<0.01)$. Weak side leg knee extensor concentric contraction relative peak torque mean in the first two test speed, black athletes is significantly higher than that of the Ha runners $(\mathrm{P}<0.05)$, in the fast strength little difference $(\mathrm{P}>0.05)$. Poor two players weak side leg three joint extensor concentric capacity of HA athletes, especially the hip and ankle. It also shows that the coordination development of the bilateral muscle strength in the training of the athletes is not enough, and the training of the weak side muscles should be strengthened. From the table can also be seen in two groups of athletic lower limb flexion and extensor relative peak torque value is in accordance with the hip, knee and ankle decreasing trend, indicating that the large joint muscle strength is larger, and the study results are consistent. $\mathrm{r}=0.612(\mathrm{P}<0.01) \quad \mathrm{r}=0.642(\mathrm{P}<0.01)$ study also found that the weak side leg hip extensor strength, knee and ankle of the fast extensor strength and standing vertical jump and vertical jump performance were closely related, hip extensor strength and vertical jump and standing vertical jump performance correlation coefficient $(\mathrm{RP}<0.01)$; knee extensor strength and vertical jump and standing vertical jump performance correlation coefficient $\mathrm{RP}<0.05$ ); joint of the fast extensor strength and vertical jump and standing vertical jump performance correlation coefficient ( RP $<0.01)$. Weak side leg three joint extensor centripetal contraction force difference, especially hip maximum strength, fast strength of ankle extensor differences is the influence of athletic foot vertical jump record.

\subsection{Comparative Analysis of Relative Peak torQue of Knee Joint Eccentric Contraction}

The takeoff knee extensor is to participate in the concession of the main muscle group, if muscles yielding ability is bad, will result in large amplitude of the buffer, and the impact of bouncing effect. So this study tested the eccentric contraction of the subjects, and the test results were shown in Table 6.
From Table 6 we can see that: there was significant difference $(\mathrm{P}<0.05)$ two groups of athletes leg extensor centrifugal strength, weak side leg two very significant difference $(\mathrm{P}<0.01)$, visible black athletes knee extensor concession and strong contraction in Ha body athletes. Study also found that HA athlete knee angle of maximum buffer larger, longer buffer time, which with knee extensor contraction ability difference has a direct relationship. And in the study that: the opposite sides of the knee extensor concessions contractility and longitudinal jump and standing vertical jump in varying degrees of correlation. Legs and vertical jump and standing vertical jump correlation coefficients were $\mathrm{R}=0.691$ $(\mathrm{P}<0.01), \mathrm{R}=0.569(\mathrm{P}<0.01)$; weak side leg and vertical jump and standing vertical jump correlation coefficients were: $\mathrm{R}=0.566(\mathrm{P}<0.01), \mathrm{R}=0.552(\mathrm{P}<0.05)$. Two groups of athletes knee extensor eccentric capacity of differences is one of the reasons for the two groups of athletes jumping ability difference.

Comparison and analysis of the peak torque of the same muscle in the left and right the muscle of the same name refers to the same two muscles as the right and left parts. According to the literature recorded, about the same name of muscle strength differences can not exceed $10 \%$, otherwise weak side muscles easily injured. The difference between left and right muscle is (strong side muscle strength and weak side muscle strength) / strong side muscle strength $\times 100 \%$, and the test results are shown in Table 7 and $\mathbf{8}$.

From Tables $\mathbf{7}$ and $\mathbf{8}$ can be seen in the three test speed black athletes both flexor and extensor muscle differences of the same name over $10 \%$ of the number of Ha athletes were higher than that of black athletes. The athletes lower limb extensor muscle strength level is directly influenced the bounce force. Extensor of black athletes in the low-speed test, hip and ankle joints the 1 million, accounted for $10 \%$ of the total number of left and right homonymous muscle strength difference of more than $10 \%$, and this difference in the other speed test for 90 . Hei athletes on both sides of the same name extensor differences larger: in low speed testing, hip and ankle joints the 5 people, accounted for about $50 \%$ of the total number of the number of homonymous muscle differ by more than $10 \%$, when the other two speed test, each joint at least about $20 \%$ the number of homonymous muscle differences of more than $10 \%$; flexor also showed ha body athletes around the homonymous muscle were significantly higher than the black athletes. The muscular strength of the left and right leg muscles of the $\mathrm{Ha}$ athlete is poor. About 
Table 7. The number of the same name about extensor peak torque difference of more than $10 \%$ of the control table (\%).

\begin{tabular}{|c|c|c|c|c|c|c|c|c|c|c|c|c|}
\hline \multirow{3}{*}{ Joint } & \multicolumn{4}{|c|}{$60 \% \mathrm{CON})$} & \multicolumn{4}{|c|}{$180 \%$ CON) } & \multicolumn{4}{|c|}{$\left.300^{\circ} / \mathrm{s} \quad \mathrm{CON}\right)$} \\
\hline & \multicolumn{2}{|r|}{ Hei } & \multicolumn{2}{|c|}{ Ha } & \multicolumn{2}{|c|}{ Hei } & \multicolumn{2}{|c|}{ Ha } & \multicolumn{2}{|c|}{ Hei } & \multicolumn{2}{|c|}{ Ha } \\
\hline & $\begin{array}{c}\text { Person- } \\
\text { Time }\end{array}$ & Percentage & $\begin{array}{c}\text { Person- } \\
\text { Time }\end{array}$ & Percentage & $\begin{array}{c}\text { Person- } \\
\text { Time }\end{array}$ & Percentage & $\begin{array}{c}\text { Person- } \\
\text { Time }\end{array}$ & Percentage & $\begin{array}{c}\text { Person- } \\
\text { Time }\end{array}$ & Percentage & $\begin{array}{c}\text { Person- } \\
\text { Time }\end{array}$ & Percentage \\
\hline Hip & 1 & $10 \%$ & 5 & $50 \%$ & 0 & $0 \%$ & 2 & $20 \%$ & 0 & $0 \%$ & 2 & $20 \%$ \\
\hline Knee & 0 & $0 \%$ & 2 & $20 \%$ & 0 & $0 \%$ & 4 & $40 \%$ & 0 & $0 \%$ & 2 & $20 \%$ \\
\hline Ankle & 1 & $10 \%$ & 5 & $50 \%$ & 0 & $0 \%$ & 3 & $30 \%$ & 0 & $0 \%$ & 2 & $20 \%$ \\
\hline
\end{tabular}

Table 8. The number of the same name about the flexor peak torque difference of more than $10 \%$ of the control table (\%).

\begin{tabular}{|c|c|c|c|c|c|c|c|c|c|c|c|c|}
\hline \multirow{3}{*}{ Joint } & \multicolumn{4}{|c|}{$60 \% \mathrm{CON})$} & \multicolumn{4}{|c|}{$180 \%$ CON) } & \multicolumn{4}{|c|}{$300 \%$ CON) } \\
\hline & \multicolumn{2}{|c|}{ Hei } & \multicolumn{2}{|c|}{ Ha } & \multicolumn{2}{|c|}{ Hei } & \multicolumn{2}{|c|}{ Ha } & \multicolumn{2}{|c|}{ Hei } & \multicolumn{2}{|c|}{ Ha } \\
\hline & $\begin{array}{l}\text { Person- } \\
\text { Time }\end{array}$ & Percentage & $\begin{array}{c}\text { Person- } \\
\text { Time }\end{array}$ & Percentage & $\begin{array}{c}\text { Person- } \\
\text { Time }\end{array}$ & Percentage & $\begin{array}{c}\text { Person- } \\
\text { Time }\end{array}$ & Percentage & $\begin{array}{c}\text { Person- } \\
\text { Time }\end{array}$ & Percentage & $\begin{array}{c}\text { Person- } \\
\text { Time }\end{array}$ & Percentage \\
\hline Hip & 0 & $0 \%$ & 3 & $30 \%$ & 1 & $10 \%$ & 2 & $20 \%$ & 0 & $0 \%$ & 2 & $20 \%$ \\
\hline Knee & 2 & $20 \%$ & 7 & $70 \%$ & 1 & $10 \%$ & 4 & $40 \%$ & 1 & $10 \%$ & 2 & $20 \%$ \\
\hline Ankle & 2 & $20 \%$ & 6 & $60 \%$ & 1 & $10 \%$ & 2 & $20 \%$ & 0 & $0 \%$ & 1 & $10 \%$ \\
\hline
\end{tabular}

homonymous muscle differences, not only in on both sides at the same time forced weaker side muscle is susceptible to damage. The author also suggests that if the left and right homonymous muscle strength level difference is too large, especially in fast movement on both sides of the muscle strength can not achieve a coordinated, will affect to jump in both feet of the effect.

Through the analysis of basketball players' spring can be found in the non professional basketball athletes exhibited weak side joint muscle strength level low and about homonymous muscle force and the degree of difference between the larger, so that to jump in with both feet on both sides of the muscle is not up to the coordinated, and the influence of take-off. Professional team basketball players showed weak muscle strength of the muscle is also high, muscle strength of left and right muscle difference is small, and it is conducive to the feet off when muscle group coordination force. The strength of the weak lateral hip joint and the strength of the ankle joint are the important reasons for the impact of the two groups of athletes' feet off. In view of the above situation, we should pay attention to the coordination development between the muscles, especially the muscle strength in the lower limbs, and to carry out targeted training for the weak side muscle.

\section{CONCLUSION}

This paper, from the spring of biomechanical analysis and endurance to dunk a basketball biomechanical analysis of two aspects resolves the basketball player to dunk a basketball biomechanical factors, and obtained the dunk technique which is mainly affected by the spring just hover technology's influence. Dunk technology has become one of the main means of scoring the basketball game, the view of the strong, with morale and attract the audience. Using the method of slam dunk in the game is varied, and difficult to defend, the success rate is high, it is easy to foul. After the proposal of the basketball training in the dunk included in the training program and dunk knowledge popularity in a variety of youth basketball training camp, has the ability to dunk the personnel training. To deepen the study of dunks, dunk development support technology theoretically.

With the improvement of basketball level and the enhancement of the degree of Sports Training Science, the improvement and innovation of the research method of sports biomechanics, the organic combination of quantitative and qualitative analysis methods are important.

\section{CONFLICT OF INTEREST}

The author confirms that this article content has no conflict of interest.

\section{ACKNOWLEDGEMENTS}

Declared none.

\section{REFERENCES}

[1] J. Li, "The research methods and lateral quantities of sports biomechanics," Chinese Journal of Sports Science Society, vol. 19, no. 2, pp. 201-225, 1999.

[2] M. Sun, "Basketball,” People's sports press, pp. 23-40, 1996.

[3] Y. Yu, "About volleyball endurance Teaching and research," Journal Of Shanghai Institute Of Physical Education, no. 04, 1980.

[4] X. Zheng, "Modern sports biomechanics," Beijing: National Defense Science and Technology Press, pp. 2-4, 2002.

[5] S. Zhou, "Retrospect and Prospect of sports biomechanics research," Shanxi Normal University Journal of Physical Education Institute, vol. 15, no. 1, pp. 73-77, 2000. 
[6] Z. Li, "Analysis of the status quo of sports biomechanics in China," Shanghai Institute Of Physical Education To Report, vol. 21, no. 1, pp. 23-26, 1997.

[7] J. Li, "Progress and Prospect of sports biomechanics research," Zhejiang sports science, vol. 21, no. 1, pp. 42-46, 1999.

[8] J. Wang, "Thinking about the development of domestic sports biomechanics," Tianjin University of Sport Newspaper, vol. 18, no. 4, pp. 33-36, 2003.

[9] X. Deng, "Analysis on spring mechanics of basketball players," Sports science and technology in China, no. 20, pp. 58-59, 1999.

[10] Z. Yu, and Q. Guo, "A comparative study of the three knee joint muscle test of the lower limbs of the volleyball and basketball players in the lower limbs," Sports Science, vol. 20, no. 1, pp. 73$78,2000$.
[11] G. Zhang, and S. Yu, "Flexor torque test analysis of hip, knee, ankle extensor athletes," Chinese Journal of Sports Medicine, vol. 15, no. 2, pp. 40-44, 1992.

[12] Yi. Li, "Application and training of the aggressive defense of college students in basketball match," Liaoning sports science and technology, vol. 30, no. 1, pp. 58-59, 2000.

[13] Z. Li, "Basketball skills and tactics ladder training method," Beijing: People's Sports Press, pp. 97-98, 1997.

[14] W. Xu, and Q. Li, "Analysis of the movement structure and classification of basketball mobile technology," Hubei sports science and technology, vol. 12, no. 21, pp. 472-473, 2002.

[15] W. Bi, "Basketball technical analysis and Application," Journal of Shandong Sports Institute, vol. 03, pp. 1991-1999, 2003.

(C) Daliang Zhou; Licensee Bentham Open.

This is an open access article licensed under the terms of the (https://creativecommons.org/licenses/by/4.0/legalcode), which permits unrestricted, noncommercial use, distribution and reproduction in any medium, provided the work is properly cited. 